\title{
Enhanced leptin synthesis and secretion In vitro by human adipocytes from type 2 diabetic donors occurs only under hyperinsulinaemic conditions
}

\begin{abstract}
Leptin is $16 \mathrm{kDa}, 146$ amino acid residue peptide hormone that is thought to play a central role in the regulatory role of adipose tissue on energy metabolism. Leptin is synthesised by adipocytes and released to the circulation, where it acts as an afferent signal to the central nervous system, relaying information about the degree of adiposity to the hypothalamus. Hyperthalomic leptin resistance is associated with obesity and an increased risk of type 2 diabetes and hyperinsulinemia. However, the direct effects of hyperinsulinaemia on leptin secretion by adipocytes remain unclear. The aim of this study was to examine leptin secretion In vitro by adipocytes from type 2 diabetic and normal donors under normoinsulinaemic and hyperinsulinaemic conditions. The results of this study showed that for normal adipocytes, exposure to 10 and $100 \mathrm{ng} / \mathrm{ml}$ insulin for 72 hours caused an increased leptin secretion of $5.68 \pm 0.82 \mathrm{pg} / \mathrm{ml} / 10^{4}$ cells $(\mathrm{P}<0.001)$ and $16.21 \pm 2.72 \mathrm{pg} / \mathrm{ml} / 10^{4}$ cells $(\mathrm{P}<0.001)$ respectively. For type 2 diabetic adipocytes, however, 72hours insulin exposure at 10 and $100 \mathrm{ng} / \mathrm{ml}$ produced non-significant and $3.10 \pm 0.36 \mathrm{ng} / \mathrm{ml} / 10^{4}$ cells $(\mathrm{P}<0.039)$ levels of leptin secretion. Following exposure for 120 hours diabetic adipocytes exposed to 10 and $100 \mathrm{ng} / \mathrm{ml}$ insulin showed increased leptin secretion of $25.92 \pm 1.74 \mathrm{ng} / \mathrm{ml} / 10^{4}$ cells $(\mathrm{P}<0.001)$ and $38.56 \pm 2.48 \mathrm{ng} / \mathrm{ml} / 10^{4}$ cells $(\mathrm{P}<0.001)$ respectively. These values were significantly greater than those for normal adipocytes $(\mathrm{P}<0.003$ and $\mathrm{P}<0.013$ respectively). These results suggest that both normal and supraphysiological insulin concentrations directly stimulate secretion of leptin by adipocytes from both normal and type 2 diabetic donors, but the effect is greatest for type 2 diabetic adipocytes following extended periods of supraphysiological insulin treatment. The relationship between insulin and leptin concentrations in obesity and type 2 diabetes warrants further investigation to uncover potential therapeutic targets.
\end{abstract}

Volume 3 Issue 6 - 2016

\author{
David Cadagan, ${ }^{1,2}$ Robert Barrington, ${ }^{2}$ Paul \\ Murray,' Stephen Merry ${ }^{2}$ \\ 'Institute of Cancer and Genomic Sciences, University of \\ Birmingham, UK \\ ${ }^{2}$ Biological and Biomedical Sciences, Staffordshire University, UK
}

Correspondence: David Cadagan, Staffordshire University, Biological and Biomedical Sciences, Science Centre, Leek Road, Stoke-on-Trent ST4 2DF, UK, Tel 0178229 5400, E-mail David.Cadagan@staffs.ac.uk

Received: September 23, 2016 | Published: October 12, 2016

Keywords: adipocyte, type 2 diabetes, insulin, leptin, adipokines, hormones, steroidogenesis

Abbreviations: AP, alkaline phosphatise; BMI, body mass index; ELISA, enzyme-linked immonosorbent assay; PAGE, polyacrylamide gel electrophoresis; PBS, phosphate buffered saline; PTEN, phosphatase and tensin homolog; TBS, tris buffered saline

\section{Introduction}

Prior to the last two decades adipose tissue was often regarded as simply a storage site for excess energy. More recently, however, it has emerged as a complex endocrine organ; the full complexity of which is yet to be understood. Research has shown that adipocytes are capable of secreting many varied bioactive peptides and proteins called adipokines. These act as autocrine, paracrine and endocrine signalling molecules. ${ }^{1,2,3}$

A greater understanding of the importance of adipose tissue in whole body homeostasis as well as its effects on particular physiological processes has occurred with the discovery of roles for adipose tissue in inflammation, blood pressure regulation, lipid metabolism, insulin sensitivity and coagulation. ${ }^{4}$ In particular, irregularities in adipokine secretion may be associated with weight gain since adipokine dysfunction has been shown to cause dysfunction in the energy regulatory mechanisms of the body. ${ }^{2,5,6}$

The adipokine leptin contributes to an endocrine circuit that regulates energy homeostasis. ${ }^{7,8}$ It activates receptors in the hypothalamus to modulate the release of the anorexigenic and exogenic peptides, and in this regard leptin acts as an afferent signal in a negative feedback loop from adipocytes to the hypothalamus that regulates adiposity in mammals. ${ }^{9}$ Changes to the normal physiological regulation of leptin may therefore be expected to lead to weight gain and obesity, and may have also other physiological consequences in other hormonal circuits. Understanding the causative factors that may affect the production, availability and function of leptin is therefore important in order to understand and potentially treat obesity and its consequences.

The role of leptin in obesity has been shown to involve complex interactions with other adipokines and insulin resistance. ${ }^{10,11}$ Kolaczynski et al. ${ }^{12}$ found serum leptin concentrations to be correlated with body mass index (BMI) and also to be raised in response to long-term hyperinsulinaemia in vitro. Additional rodent studies have suggested that high leptin concentrations result in decreased hypothalamic sensitivity to leptin. ${ }^{13}$ Such changes to the insulin and leptin system are characterized as obesity-associated insulin resistance, a condition that is associated to the onset of type 2 diabetes. $^{14}$

Although the development of high circulatory leptin levels may be affected by decreased hypothalamic sensitivity, no examination of leptin synthesis and secretion by adipocytes taken from diabetic donors has been undertaken under hyperinsulinaemic conditions. Such an examination is important because it may show a direct influence of insulin on leptin secretion by adipocytes, and this may contribute 
to the high circulatory levels seen in obesity. Furthermore, the identification of raised insulin as a therapeutic target for the reversal of the raised levels of leptin seen in obesity could consequently provide a mechanism to reverse hypothalamic leptin insensitivity. We therefore examined the interaction that may exist between insulin and leptin at the level of the adipocyte by measuring the effects of insulin treatment on leptin secretion by adipocytes derived from normal and from diabetic donors which have been shown to exhibit insulin resistance in vitro. ${ }^{15} \mathrm{~A}$ study in vitro was designed to avoid potential confounding influences from other factors that have been shown to enhance leptin secretion from adipocytes such as angiotensin II, ${ }^{16}$ ghrelin, ${ }^{17}$ oleic acid ${ }^{18}$ and Wnt pathway activation. ${ }^{19}$

\section{Materials and methods}

\section{Cell culture}

Murine 3T3-L1 cells (kindly donated by Nottingham University, UK) and pooled human preadipocytes from normal and type 2 diabetic donors (Lonza) were maintained in $25 \mathrm{~cm}^{2}$ tissue culture flasks at $37^{\circ} \mathrm{C}$ in RPMI 1640 medium supplemented with $10 \%$ foetal bovine serum and with a gas phase of $3 \% \mathrm{CO}_{2}$ in air. Cell suspensions were prepared by trypsinisation and viable cells (those excluding $0.2 \%$ trypan blue) were counted in a Neubauer haemocytometer. Normal and type 2 diabetic human adipocytes were compared for glucose uptake and differentiation following passage to ensure the phenotype was retained. Murine 3T3-L1 cells cultured in medium supplemented with $10 \mathrm{ng} / \mathrm{ml}$ insulin ${ }^{16}$ were used as positive controls. For leptin secretion assays $5 \times 10^{3}$ normal or type 2 diabetic human preadipocytes were plated into the wells of triplicate 24 well plates in $300 \mu \mathrm{l}$ of medium. Differentiation of human preadipocytes was induced by adding medium supplemented with $200 \mu \mathrm{M}$ indomethacin, 3-Isobutyl- 1-methylxanthine, $0.1 \mu \mathrm{M}$ dexamethasone, $1 \mu \mathrm{M}$ insulin, $1 \%$ L-Glutamine, $10 \%$ foetal bovine serum and GA-1000 (Lonza). After 10days, when oil red O staining showed lipid droplet formation, ${ }^{20}$ the medium was replaced with medium containing 0,10 or $100 \mathrm{ng} /$ $\mathrm{ml}$ insulin and the cells were incubated for a further $0,4,8,24,48$, 72 or 120 hours prior to removing both the conditioned medium and harvesting the cells to form lysates. Leptin was estimated in the in the medium using ELISA and in the lysates by western blotting.

\section{ELISA}

Leptin in cell culture medium was measured using the Human Leptin Quantikine ELISA Kit (R\&D Systems) according to the manufacturer's instructions. Absorbance was measured at 570nm and the range of sensitivity of the kit was $1.56-100 \mathrm{pg} / \mathrm{ml} / 10^{4}$ cells.

\section{Western blotting}

To prepare lysates cell monolayers were washed with phosphate buffered saline (PBS) and harvested by trypsinisation. Cells were counted, centrifuged at $250 \mathrm{x}$ g for 10 minutes at $4^{\circ} \mathrm{C}$ and resuspended in lysis buffer $(25 \mathrm{mM}$ Tris $\mathrm{pH} 7.5,300 \mathrm{nM}$ sucrose, $10 \mathrm{mM}$ monothyioglycerol, $1 \mathrm{mM}$ EDTA, $1 \%(\mathrm{v} / \mathrm{v})$ Igepal, $0.002 \%$ protease inhibitor cocktail, $0.01 \%$ phosphatase inhibitor II (Sigma)). Lysates were stored at $-80^{\circ} \mathrm{C}$. Proteins were resolved using $10 \%$ polyacrylamide gel electrophoresis (PAGE). The Bradford method ${ }^{21}$ was used to determine protein concentration in cell lysates and each lane of the gel was loaded with $100 \mathrm{~g}$ of sample protein taken from treated normal or type 2 diabetic human adipocytes, or control cells. $10 \mu \mathrm{l}$ of Kaleidoscope pre-stained molecular weight markers (Sigma) was used to facilitate protein size determination. Electrophoresis was conducted in $25 \mathrm{mM}$ Tris, $19 \mathrm{mM}$ glycine buffer for 1 hour at $40 \mathrm{~mA} .{ }^{6}$ Proteins were then electroblotted onto nitrocellulose membranes in ice cold transfer buffer $(25 \mathrm{mM}$ Tris, $80 \mathrm{mM}$ glycine, $20 \%(\mathrm{v} / \mathrm{v})$ methanol) using a Miniprotean blotting system (Bio-Rad) at $100 \mathrm{v}^{6}$ for 2 hours.

Membranes were then blocked by immersion in 5\% dried milk in $25 \mathrm{mM}$ Tris, $150 \mathrm{mM} \mathrm{NaCl}$ (TBS) for 1hour. Anti-leptin antibody (antiOB, R\&D Systems) was then added and membranes were incubated overnight at $4^{\circ} \mathrm{C}$, washed (10minutes x6) with $0.1 \%$ Tween in TBS followed by washes (10minutes x 3) with TBS. Membranes were then incubated with alkaline phosphatase (AP) conjugated secondary antibodies (Bio-Rad) in 3\% dried milk in TBS for 2 hours at room temperature with gentle agitation. The membrane was washed again as described above and visualized by incubating (10minutes) with Immuno-Star AP Chemiluminescence enhancer $(50 \mu \mathrm{l})$ and substrate solution $(2.5 \mathrm{ml}$, Bio-Rad) evenly coating the nitrocellulose blot. Blots were stripped using glycine buffer (200mM glycine $\mathrm{pH} 2.2$, $0.1 \%$ sodium dodecyl sulphate, $1 \%$ Tween 20 ) prior to treatment with anti- $\beta$-actin antibody (Sigma). Results were analyzed by densitometry and normalised using a Chemi Doc (v. 4.2.1) imaging system ${ }^{22}$ with $\beta$-actin as reference.

\section{Data and statistical analysis}

All experiments were repeated at least once on different occasions and data are presented from typical experiments involving five replicates. Data sets were subjected to Shapiro-Wilk normality tests and expressed as mean \pm s.d. Subsequent comparisons were made using two tailed Student's $t$-test with Bonferroni correction. Values of $\mathrm{P}<0.05$ were considered significant. Graph Pad Prism software (v. $5.0 \mathrm{~b})$ was used.

\section{Results}

Increased leptin production in response to insulin was not observed at time points earlier than 72 hours. Data are therefore presented for 72 and 120 hours treatments only.

\section{Effect of insulin on leptin secretion from adipocytes from normal human donors}

ELISA showed that insulin treatment of normal human adipocytes for 72hours caused an increased leptin secretion of $5.68 \pm 0.82 \mathrm{pg} /$ $\mathrm{ml} / 10^{4}$ cells $(\mathrm{P}<0.001)$ at a physiological concentration $(10 \mathrm{ng} / \mathrm{ml})$ and of $16.21 \pm 2.72 \mathrm{pg} / \mathrm{ml} / 10^{4}$ cells $(\mathrm{P}<0.001)$ at a supraphysiological concentration $(100 \mathrm{ng} / \mathrm{ml}$, Figure 1). Insulin treatment of these cells for 120 hours increased leptin secretion approximately a further twofold at both physiological $\left(12.76 \pm 1.04 \mathrm{pg} / \mathrm{ml} / 10^{4}\right.$ cells, $\left.\mathrm{P}<0.001\right)$ and supraphsiological $\quad\left(26.94 \pm 0.95 \mathrm{pg} / \mathrm{ml} / 10^{4}\right.$ cells, $\left.\quad \mathrm{P}<0.001\right)$ concentrations (Figure 1).

\section{Effect of insulin on leptin secretion from adipocytes from human type-2 diabetic donors}

ELISA showed that, unlike normal adipocytes, insulin treatment for 72 hours of type 2 diabetic human adipocytes at a physiological concentration $(10 \mathrm{ng} / \mathrm{ml})$ demonstrated no observable stimulation of leptin secretion. However, a supraphysiological insulin concentration $(100 \mathrm{ng} / \mathrm{ml})$ for 72 hours did increase significantly leptin secretion to $3.10 \pm 0.36 \mathrm{pg} / \mathrm{ml} / 10^{4}$ cells $(\mathrm{P}<0.039)$. Incubation periods of 120 hours increased leptin secretion at least twelvefold at both physiological $\left(25.92 \pm 1.74 \mathrm{pg} / \mathrm{ml} / 10^{4} \quad\right.$ cells, $\left.\quad \mathrm{P}<0.001\right)$ and supraphysiological $\left(38.56 \pm 2.48 \mathrm{pg} / \mathrm{ml} / 10^{4}\right.$ cells, $\left.\mathrm{P}<0.001\right)$ insulin concentrations (Figure 2). 


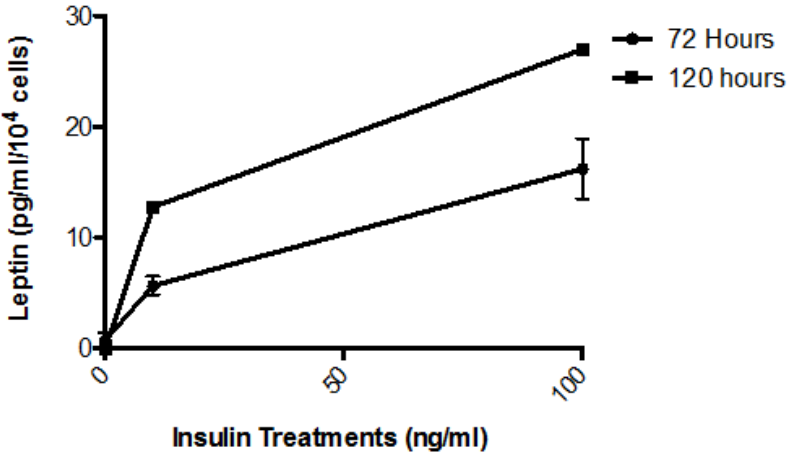

Figure I Effect of insulin on leptin secretion by normal human adipocytes.

Cells were treated with media supplemented with $0 \mathrm{ng} / \mathrm{ml}, 10 \mathrm{ng} / \mathrm{ml}$ or $100 \mathrm{ng} /$ $\mathrm{ml}$ insulin for 72 or 120 hours. Leptin concentrations in the media were then determined by ELISA. Treatment at both insulin concentrations and times resulted in significant $(\mathrm{P}<0.00 \mathrm{I}, \mathrm{n}=5)$ increases in leptin secretion from basal levels. The insulin effect is seen to be both concentration dependent and time dependent. Error bars are omitted when their range would be smaller that the symbol used to indicate mean value.

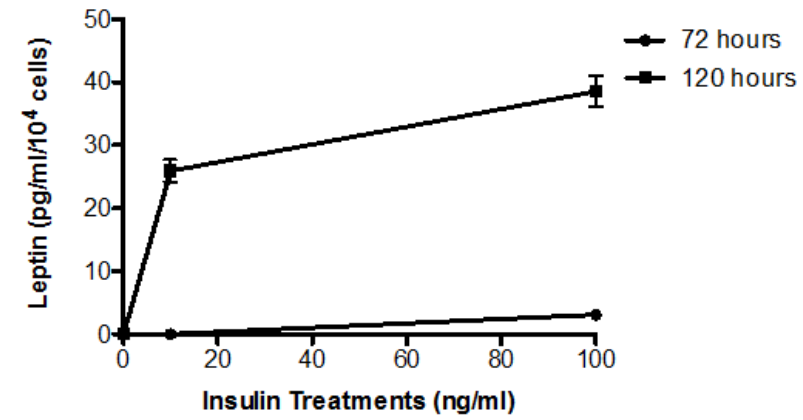

Figure 2 Effect of insulin on leptin secretion by type 2 diabetic human adipocytes.

Cells were treated with media supplemented with $0 \mathrm{ng} / \mathrm{ml}, 10 \mathrm{ng} / \mathrm{ml}$ or $100 \mathrm{ng} /$ $\mathrm{ml}$ insulin for 72 or 120 hours. Leptin concentrations in the media were then determined by ELISA. Insulin treatment at $10 \mathrm{ng} / \mathrm{ml}$ resulted in a significant $(P<0.039, n=5)$ increase in leptin secretion from basal levels only after 120 hours. Insulin treatment at $100 \mathrm{ng} / \mathrm{ml}$ for both times resulted in significant $(P<0.001, n=5)$ increases in leptin secretion from basal levels. The insulin effect is seen to be both concentration dependent and time dependent with the time dependency particularly marked $(\mathrm{P}<0.00 \mathrm{I}, \mathrm{n}=5$ at both insulin concentrations). Error bars are omitted when their range would be smaller that the symbol used to indicate mean value.

\section{Comparison of insulin effects on adipocytes from normal and type-2 diabetic samples}

Leptin concentrations following 120 hours of insulin treatment were examined in both culture media $(n=5)$ and cell lysates $(n=3)$ using ELISA and western blotting respectively. ELISA data (previously shown as Figure $1 \& 2$ ) showed that type 2 diabetic human adipocytes secreted significantly more leptin than normal human adipocytes following treatment with physiological $(10 \mathrm{ng} / \mathrm{ml}, \mathrm{P}<0.003)$ and supraphysiological $(100 \mathrm{ng} / \mathrm{ml}, \mathrm{P}<0.013)$ concentrations of insulin for 120 hours. ELISA data for 120 hour treatments were supported by western blot results showing increased leptin band intensity at this time point following treatment of both normal human and type 2 diabetic human adipocytes with insulin at physiological $(10 \mathrm{ng} / \mathrm{ml}$, $\mathrm{P}<0.001)$ and supraphysiological $(100 \mathrm{ng} / \mathrm{ml}, \mathrm{P}<0.001)$ concentrations (Figure 3).

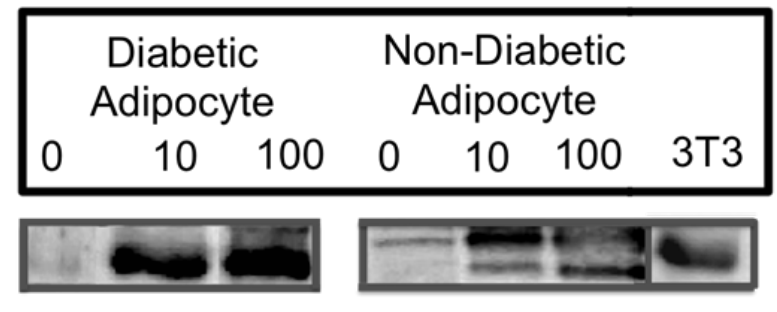

Leptin 16kDa

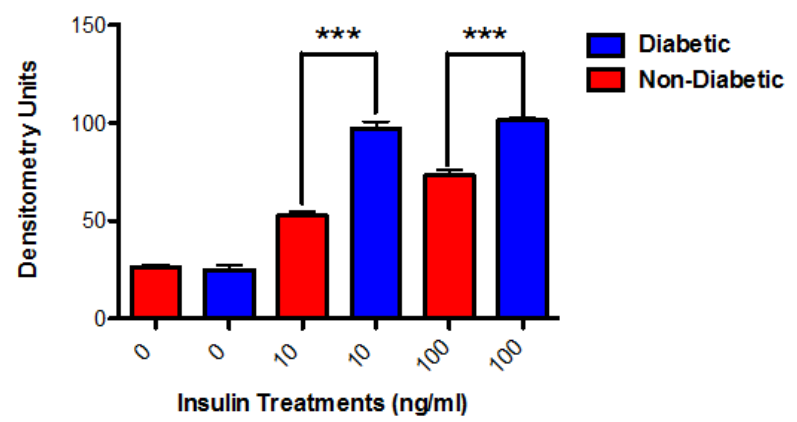

Figure 3 Effect of insulin on leptin concentrations in normal and type 2 diabetic human adipocyte cell lysates.

Cells were treated with media supplemented with $0 \mathrm{ng} / \mathrm{ml}, 10 \mathrm{ng} / \mathrm{ml}$ or $100 \mathrm{ng} /$ $\mathrm{ml}$ insulin for I20hours. Leptin production (16kDa MW) was then determined by densitometry of immunostained western blots of cell lysates. At both insulin concentrations type 2 diabetic adipocytes showed greater amounts of leptin compared to their non-diabetic counterparts $(P<0.003, n=5,10 \mathrm{ng} / \mathrm{ml}$; $\mathrm{P}<0.00 \mathrm{l}, \mathrm{n}=5, \mathrm{l}$.00ng/ml).

\section{Discussion}

Starvation has been shown to decrease both plasma insulin and leptin concentrations in non-diabetic rodents. ${ }^{23}$ Conversely, obesity in humans is often associated with hyperinsulinaemia and hyperleptinaemia ${ }^{12,24}$ with serum leptin concentrations correlated with BMI. ${ }^{12}$ Since obesity is associated with the development of metabolic conditions such as type 2 diabetes. ${ }^{7,25}$ relationships between insulin and leptin secretion have become of great interest to researchers. In particular, leptin may be a therapeutic target to circumvent both obesity and diabetes. Cammisotto \& Bukowiecki ${ }^{26}$ found that insulin stimulated leptin expression and secretion in adipocytes in vitro and these results have been replicated in vivo..$^{25,26}$

While studies have shown that leptin secretion in the absence of diabetes is positively associated to insulin, ${ }^{12,27,28}$ others have produced conflicting results with Mac Dougald et al. ${ }^{9}$ and Sliecker et al. ${ }^{29}$ both reporting no or very modest leptin rises following insulin treatment. To attempt to resolve these conflicting findings and to further extend the data to include adipocytes from type 2 diabetics, the present study investigated the effect of both physiological $(10 \mathrm{ng} / \mathrm{ml})$ and supraphysiological $(100 \mathrm{ng} / \mathrm{ml})$ concentrations of insulin on leptin secretion by adipocytes from normal human and type 2 diabetic human donors. The insulin concentrations chosen reflect typical values observed in the serum of non-diabetic and diabetic humans, and also those used in previous investigations of the role of leptin. ${ }^{12,27}$

Our data showed leptin to be produced and secreted in an insulin dose dependent manner in both cell types. However, increasing incubation times with insulin 1.7-fold from 72 to 120 hours resulted in an approximately 2-fold increase in the amount of leptin secretion by normal human adipocytes (Figure 1), but a more than 12-fold 
increase for type 2 diabetic human adipocytes (Figure 2). A possible interpretation of these findings is a combination of

i. The onset of secretion of leptin in the case of the diabetic adipocytes was delayed compared to their normal counterparts and

ii. When stimulated, the rate of secretion of leptin by diabetic adipocytes was greater than their normal counterparts. The eventual amount of leptin secreted by type 2 diabetic human adipocytes at a supraphysiological insulin concentration was significantly higher than that secreted by normal adipocytes $(\mathrm{P}<0.013)$.

These findings were obtained from determinations of leptin concentrations in cell culture supernatants using ELISA. They were mirrored by determinations of leptin in cell lysates using antibody staining of western blots (Figure 3). Overall, our data may provide some explanations for the previously described conflicting results concerning the reduced sensitivity of type 2 diabetic adipocytes to insulin; a phenomenon termed insulin resistance. ${ }^{30,31}$ If adipocytes of type 2 diabetics, compared to their normal counterparts, have

i. a delayed response to insulin and

ii. a wider range of eventual responsiveness to changes in insulin concentration, the extent of insulin treatment that they receive will have major effect on their observed cellular responses.

In this context Kolaczynski et al. ${ }^{12}$ found that short-term hyperinsulinemia ( 74 to $>10,000 \mu \mathrm{U} / \mathrm{ml}$; equivalent to approximately 3 to $>300 \mathrm{ng} / \mathrm{ml}$ ) had no effect on circulating leptin concentration or levels of leptin in vitro. Similar results were also obtained by Haffner et al., ${ }^{27}$ but MacDougald et al., ${ }^{9}$ found that insulin treatment of rats with induced diabetes increased leptin mRNA in adipose tissue to $60 \%$ of that of their non-diabetic counterparts within 4 hours. We propose support for the theory of Haffner et al., ${ }^{27}$ of a control mechanism for the regulation of leptin secretion, which is in place for the fasting or low circulatory insulin state. This typically leads to insulin sensitivity in adipocytes of non-diabetics. ${ }^{9}$ However, this mechanism seems to be delayed in our diabetic human adopocytes and results in hypersensitivity following prolonged exposure to insulin. The work of Kurlawalla-Martinez et al., ${ }^{32}$ supports such a control mechanism and identified phosphatase and tensin homolog (PTEN) as a potential negative regulator of insulin sensitivity within the PI3K/Akt pathway because loss of PTEN in mutant mice models led to improved insulin sensitivity. Intracellular calcium may also be an important factor because it is upregulated by insulin, ${ }^{33}$ which causes robust Akt phosphorylation leading to increased leptin secretion. It is possible that prolonged exposure of adipocytes to insulin may increase leptin secretion by a combination of such mechanisms. Furthermore, it has been suggested that a delayed effect of insulin treatment on leptin secretion in adipocytes is compatible with the effect being indirect ${ }^{12}$ and additional physiological factors may be involved in vivo with strong candidates being hormonal ${ }^{34}$ and inflammatory ${ }^{35,36}$ influences, and a role for the hypothalamus. ${ }^{23}$ Should the delayed effect of insulin treatment on leptin secretion in adipocytes from type 2 diabetic donors be proven in subsequent studies, the phenomenon may be analogous to the biphasic response of insulin secretion to glucose ${ }^{37}$ where impairment of early and late phase insulin secretion leads to different clinical outcomes. ${ }^{38}$

A final point is that the contrasting findings regarding the effect of insulin on leptin secretion may reflect the different situations in which data has been collected. For example, the $o b / o b$ mouse is perhaps the most commonly used model for investigating the metabolic effects of obesity including diabetes. These mice have a defect in the gene that produces leptin and the administration of leptin corrects the deficiency in these animals. However, this contrasts with the observation that obese humans typically have high levels of leptin in their serum. ${ }^{12}$ Furthermore, the few obese humans who do have leptin deficiency do not typically develop diabetes. ${ }^{39}$

\section{Conclusion}

In conclusion our results suggest that insulin stimulates leptin secretion by both type 2 diabetic and non-diabetic adipocytes in a dose dependent manner. Secretion is also increased following extended insulin incubation. For normal human adipocytes there was a twofold rise in leptin secretion between 72-120hours. For type 2 diabetic human adipocytes, however, shorter-term insulin incubation produced limited leptin secretion and significant increases ( $>12$-fold) occurred between 72-120hours. The data from diabetic human adipocytes contrast greatly with those obtained from normal human adipocytes and suggest that the cells from diabetic donors may have a delayed response to insulin and also a wider range of eventual responsiveness to changes in insulin concentration. We propose further examination of induced leptin secretion and subsequent PI3-Akt pathway activation following prolonged insulin incubation within type 2 diabetic human adipocytes and, in particular, the role of intercellular calcium in mediating these effects.

\section{Acknowledgements}

Support for this study was provided by Staffordshire University and the University of Birmingham. The authors would like to acknowledge the role played by Audra Jones in securing consumables to make the study possible.

\section{Conflict of interest}

Author declares that there is no conflict of interest.

\section{References}

1. Heagerty A. Obesity, diabetes and hypertension: are adipokines responsible? J Hypertens. 2016;34(Suppl 1):e20.

2. Parent AS, Lebrethon MC, Gerard A, et al. Leptin effects on pulsatile gonadotropin releasing hormone secretion from the adult rat hypothalamus and interaction with cocaine and amphetamine regulated transcript peptide and neuropeptide Y. Regul Pept. 2000;92(1-3):17-24.

3. Smith U, Khan BB. Adipose tissue regulates insulin sensitivity: role of adipogenesis, de novo lipogenesis and novel lipids. $J$ Intern Med. 2016;280(50):465-475.

4. Chondronikola M, Volpi E, Børsheim E, et al. Brown adipose tissue improves whole body glucose homeostasis and insulin sensitivity in humans. Diabetes. 2014;63(12):4089-4099.

5. Campos DB, Palin MF, Bordignon V, et al. The 'beneficial' adipokines in reproduction and fertility. Int J Obes (Lond). 2008;32(2):223-231.

6. Ionescu-Tirgoviste C, Gubceac E, Militaru M, et al. A cytomorphometric analysis of adipocytes from the omental and abdominal subcutaneous adipose tissue. Proc Romanian Acad Series B. 2001;13(3):205-228.

7. Farooq R, Amin S, Hayat Bhat M, et al. Type 2 diabetes and metabolic syndrome - adipokine levels and effect of drugs. Gynecol Endocrinol. 2016:1-4.

8. Dodd GT, Decherf S, Loh K, et al. Decherf S, Loh K, Simonds SE, Wiede F, Balland E, Merry TL, Münzberg H, Zhang Z-Y, Kahn BB, Neel BG, Bence KK, Andrews ZB, Cowley MA, Tiganis T: Leptin and insulin act on POMC neurons to promote the browning of white fat. Cell. 2015;160(1-2):88-104. 
9. Macdougald OA, Hwang CS, Fan H, et al. Regulated expression of the obese gene product (leptin) in white adipose tissue and 3T3-L1 adipocytes. Proc Natl Acad Sci USA. 1995;92(20):9034-9037.

10. Cantley J. The control of insulin secretion by adipokines: current evidence for adipocyte-beta cell endocrine signalling in metabolic homeostasis. Mamm Genome. 2014;25(9-10):442-454.

11. Li X, Jiang L, Yang M, et al. CTRP3 modulates the expression and secretion of adipokines in 3T3-L1 adipocytes. Endrocrine $J$. 2014;61(12):1153-1162

12. Kolaczynski JW, Nyce MR, Considine RV, et al. Acute and chronic effect of insulin on leptin production in humans: Studies in vivo and in vitro. Diabetes. 1996;45(5):699-701.

13. Levin BE, Dunn-Meynell AA. Reduced central leptin sensitivity in rats with diet-induced obesity. Am J Physiol Regul Integr Comp Physiol. 2002;283(4):R941-R948.

14. Qatanani M, Lazar MA. Mechanisms of obesity-associated insulin resistance: many choices on the menu. Genes Dev. 2007;21(12):1443-1455.

15. Hajer GR, van Haeften TW, Visseren FL. Adipose dysfunction in obesity, diabetes and vascular diseases. Eur Heart J. 2008;29(24):2959-2971.

16. Kim S, Whelan J, Claycombe K, et al. Angiotensin II increases leptin secretion by $3 \mathrm{~T} 3-\mathrm{L} 1$ and human adipocytes via a prostaglandin-independent mechanism. J Nutr. 2002;132(6):1135-1140.

17. Salmeron C, Johansson M, Angotzi AR, et al. Effects of nutritional status on plasma leptin levels and in vitro regulation of adipocyte leptin expression and secretion in rainbow trout. Gen \& Comp Endocrinol. 2015;210:114-123.

18. Romacho T, Glosse P, Richter I, et al. Nutritional ingredients modulate adipokine secretion and inflammation in human primary adipocytes. $\mathrm{Nu}$ trients. 2015;7(2):865-886.

19. Chen ZL, Shao WJ, Xu F, et al. Acute Wnt pathway activation positively regulates leptin gene expression in mature adipocytes. Cellular Signalling. 2015;27(3):587-597.

20. Chen XW, Jiang P, Gao JH, et al. Experimental study of human adipocyte dedifferentiation for adipose tissue engineering. Nan Fang Yi Ke Da Хие Хие Вао. 2009;29(4):606-610.

21. Bradford MM. A rapid and sensitive method for the quantitation of microgram quantities of protein utilizing the principle of protein-dye binding. Anal Biochem. 1976;72:248-254.

22. Taylor SC, Berkelmen T, Yadav G, et al. A defined methodology for reliable quantification of western blot data. Mol Biotechnol 2013;55(3):217-226.

23. Ahima RS, Saper CB, Flier JS, et al. Leptin regulation of neuroendocrine systems. Front Neuroendocrinol. 2000;21(3):263-307.
24. Steinberger J, Daniels SR. Obesity, insulin resistance, diabetes and cardiovascular risk in children. Circulation. 2003;107(10):1448-1453.

25. Kushner PA, Cobble ME, (Epub ahead of print) Hypertriglyceridemia: the importance of identifying patients at risk. Postgrad Med.

26. Cammisotto PC, Bukowiecki LJ. Mechanisms of leptin secretion from white adipocytes. Am J Physiol Cell Physiol. 2002;283(1):C244-C250.

27. Haffner SM, Miettinen H, Mykkanen L, et al. Leptin concentrations are associated with higher proinsulin and insulin concentrations but a lower proinsulin/insulin ratio in non-diabetic subjects. Int $J$ Obes Relat Metab Disord. 1998;22(9):899-905

28. Wallace AM, McMahon AD, Packard AD, et al. Plasma leptin and the risk of cardiovascular disease in the West of Scotland coronary prevention study (WOSCOPS). Circulation. 2001;104(25):3052-3056.

29. Slieker LJ, Sloop KW, Surface PL, et al. Regulation of expression of ob mRNA and protein by glucocorticoids and cAMP. $J$ Biol Chem. 1996;271(10):5301-5304

30. Odegaard JI, Chawla A. Pleiotropic actions of insulin resistance and inflammation in metabolic homeostasis. Science. 2013;339(6116):172-177.

31. Saltiel AR. Insulin resistance in the defense against obesity. Cell Metab 2012;15(6):798-804.

32. Kurlawalla-Martinez C, Stiles B, Wang Y, et al. Insulin hypersensitivity and resistance to streptozotocin-induced diabetes in mice lacking PTEN in adipose tissue. Mol Cell Biol. 2005;25(6):2498-2510.

33. Wang Y, Ali Y, Lin CY, et al. Insulin-stimulated leptin secretion requires calcium and PI3K/Akt activation. Biochem J. 2014;458(3):491-498.

34. Pektas M, Kurt AH, Un I, et al. Effects of 17b-estradiol and progesterone on the production of adipokines in differentiating 3T3-L1 adipocytes: role of Rho-kinase. Cytokine. 2015;72(2):130-134.

35. Landgraf K, Rockstroh D, Wagner IV, et al. Evidence of early alterations in adipose tissue biology and function and its association with obesity-related inflammation and insulin resistance in children. Diabetes. 2015;64(4):1249-1261.

36. Khan S, Wang CH. ER stress in adipocytes and insulin resistance: mechanisms and significance (review). Mol Med Rep. 2014;10(5):2234-2240.

37. Ahmed SI, Imam K. Diabetes: a comprehensive treatise for patients and care givers. Austin, Texas, USA: Landes Bioscience; 2014. 140p.

38. Kanat M, Norton L, Winnier D et al. Impaired early- but not late-phase insulin secretion in subjects with impaired fasting glucose. Acta Diabetol. 2011;48(3):209-217.

39. Shanik MH, Xu Y, Skrha J, et al. Insulin resistance and hyperinsulinemia: is hyperinsulinemia the cart or the horse? Diabetes Care. 2008;31(Suppl 2):S262-S268. 